\title{
A study on distribution and gender wise predilection of lip print pattern
}

\author{
Sidarth Timsinha', Suvarna Manjari Kar ${ }^{2}$ \\ ${ }^{1}$ Assistant Professor, Department of Forensic medicine, Manipal College of Medical Sciences, ${ }^{2}$ Professor, Department \\ of Forensic medicine, Manipal College of Medical Sciences, Pokhara, Nepal
}

Background: Lip prints are considered as very useful and are to be important forms of transfer evidence like finger prints. Studies have shown that even lip prints are unique for an individual and hence have the potential for personal identification. Aims and Objectives: To correlate the distribution of lip print pattern and its gender wise predominance. Material and Methods: The study comprised of 100 Nepalese medical students (50 males; 50 females). A photographic method was adopted rather than the old traditional lipstick method. The photographed lip prints were transferred into a computer to identify the character/lip print pattern. Statistical analysis was done using the SPSS (version 23.0) software package and Chi-square test was applied to evaluate the existence of correlation of lip print pattern with gender. Results: Type- II lip print pattern was frequently observed in all the four quadrants of both the sexes. This was followed by in order Type-I'> Type-I> Type-IV and Type-III lip patterns. There was a difference in gender wise distribution of lip prints. Conclusion: Further specific population based and gender specific studies on lip prints with larger sample size are required for comparison of lip prints with gender, so that a database could be created and used for representing sex differentiation.

Access this article online

\section{Website:}

http://nepjol.info/index.php/AJMS

DOI: 10.3126/ajms.v10i4.23881

E-ISSN: 2091-0576

P-ISSN: $2467-9100$

Key words: Identification; Gender; Lip prints; Forensic

\section{INTRODUCTION}

Human identification is a universal process based on scientific principles. ${ }^{1}$ Studies done so far show that even lip prints are unique for an individual and hence have the potential for personal identification like finger prints. $^{2}$

Cheiloscopy derived from the Greek word cheilos meaning "lips" is the study of the characteristics pattern of wrinkles and grooves present on the labial mucosa (sulci laborium) called as lip prints. ${ }^{2}$ In the year 1902, R. Fisher was the foremost to take notice of the biological phenomenon of the systems of furrows on the red portion of the human lips. ${ }^{3}$ In France as early as 1932 Edmond Locard was the first who recommended the use of lip prints in personal identification and criminalization. ${ }^{3,4}$ Santos, Suzuki and Tsuchihashi were among first to classify the various patterns present on human lips., 5 The significance of cheiloscopy is related to the fact that lip prints are unique to one person except in monozygotic twins like fingerprints and palatal rugae. ${ }^{7}$ In forensic investigations lip prints are considered as very useful and are to be important forms of transfer evidence like fingerprints. ${ }^{5}$ If lip prints are properly analysed it may help in establishing other relative facts like sex identification hence reducing the burden of the forensic examiner in solving the crime.

This type of study on lip prints is not piloted much among Nepalese population. So, the purpose of the study was to assess the distribution and gender wise predilection of lip print pattern among Nepalese population.

\section{MATERIALS AND METHODS}

\section{Sample collection}

The cross sectional study was conducted among 100 medical students (50 males and 50 females) of Manipal 
College of Medical Sciences, Pokhara, Nepal. The subjects aged between 18-25 years belonging to the Nepalese population were chosen by simple random method. The study was conducted over a period of 2 months, from $1^{\text {st }}$ of July to $31^{\text {st }}$ August 2018, after approval of the Institutional Ethical Committee. All the subjects were briefed about the purpose of the study and informed consent was obtained from each of them. Only healthy subjects free from oral pathologies, inflammation, abnormalities or deformities such as cleft lip, cut marks, surgical scars or lesions around the lips were included in the study.

In this study classification of lip print patterns proposed by Suzuki and Tsuchihashi ${ }^{4,5}$ was followed.

Type I: Long vertical (Clear-cut vertical grooves that run across the lips).

Type I': Short vertical (Partial length groove of type I).

Type II: Branched grooves (Branching Y-shaped pattern).

Type III: Intersected grooves (Criss-cross/'x' pattern grooves).

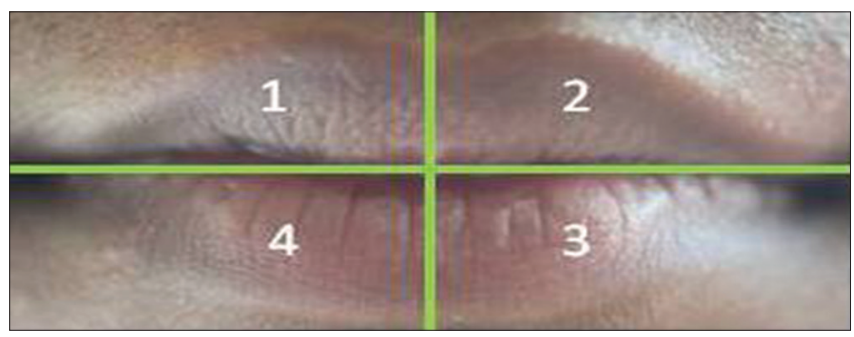

Figure 1: Lip print divided clockwise in four quadrants 1, 2, 3 and 4.
Type IV: Reticular pattern (Grooves that forms rectangular shape).

Type V: Mixed/Indefinite (Grooves that do not fall into any of the above categories, combination of two or more patterns and/or cannot be differentiated morphologically/undetermined).

The subjects were made to stand erect comfortable with head aligned in Frankfurt plane. The subjects with their lips in 'natural condition' (free of lip sticks, lip gloss or any cosmetic products) were photographed using a digital camera NIKON D5300.

\section{Lip print examination}

After transferring the photographs of the lips on a computer, firstly the lip was divided into four quadrants in a clockwise direction namely Quadrant 1, Quadrant 2, Quadrant 3, and Quadrant 4, respectively (Figure 1). The lip prints were then studied in detail with respect to each quadrant in accordance to the predominance of the lip print pattern in relation to gender. Comparison was done by studying the number and position of different lip print patterns in all the four quadrants. The photographs of lip print observed in this study is depicted in (Figure 2).

\section{Statistical analysis}

The existence of association of lip print pattern with gender was analysed using Chi square test.

The p-valve of $<0.05$ was considered as statistically significant.
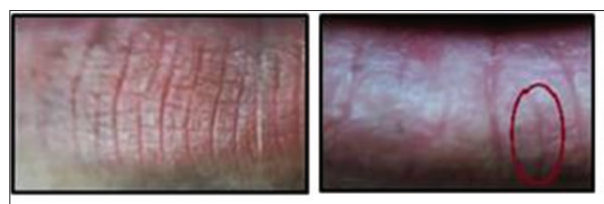

Type I

Long Vertical

Short Vertical

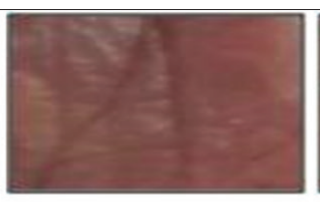

Type II

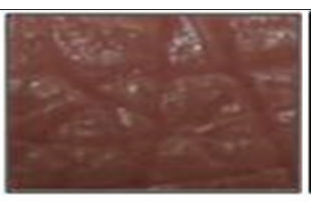

Type III

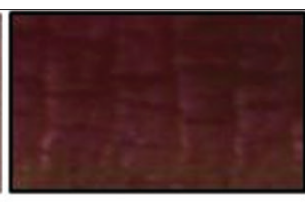

Type IV

Branched

Intersecting

Reticular

Figure 2: Photographs showing Type I to Type IV patterns of the lip prints observed in this study.

Table 1: Gender wise distribution of lip prints

\begin{tabular}{|c|c|c|c|c|c|c|}
\hline \multirow[t]{2}{*}{ Types of lip prints } & \multicolumn{2}{|c|}{ Male students $(n=50)$} & \multicolumn{2}{|c|}{ Female students $(n=50)$} & \multicolumn{2}{|c|}{ Total students $(n=100)$} \\
\hline & (200) Quadrants & $\%$ & (200) Quadrants & $\%$ & (400) Quadrants & $\%$ \\
\hline Type I & 18 & 9.00 & 11 & 5.50 & 29 & 7.25 \\
\hline Type I' & 27 & 13.50 & 18 & 9.00 & 45 & 11.25 \\
\hline Type II & 151 & 75.50 & 150 & 75.00 & 301 & 75.25 \\
\hline Type III & 4 & 2.00 & 7 & 3.50 & 11 & 2.75 \\
\hline Type IV & 0 & 0.00 & 14 & 7.00 & 14 & 3.50 \\
\hline Type V & 0 & 0.00 & 0 & 0.00 & 0 & 0.00 \\
\hline Total & 200 & 100.00 & 200 & 100 & 400 & 100.00 \\
\hline
\end{tabular}




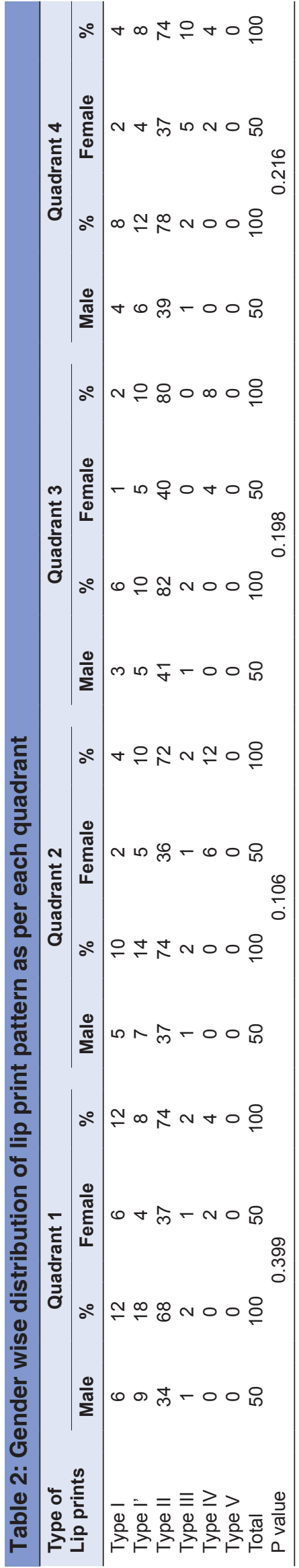

\section{RESULT}

The present study was piloted to assess the distribution and gender-wise predilection of lip print patterns. The overall distribution of lip print impressions and its types with respect to each quadrant in both the sexes is shown in (Tables 1 and 2).

In the present study analysis of lip print patterns revealed that no two lip prints were identical, thus indicating the individuality of lip prints. The commonest lip pattern found in our study was Type II pattern $(75.25 \%)$. This was followed by in order by Type I' (11.25\%), Type I (7.25\%), Type IV (3.5\%) Type III (2.75\%). There was no Type V $(0.00 \%)$ lip pattern observed in either gender in this study. There was a difference in gender wise distribution of lip prints. Among males Type II (75.50\%) and Type I' $(13.50 \%)$ lip pattern occurred more repeatedly followed by Type I $(9.00 \%)$ and Type III $(2.00 \%)$ with no Type IV and Type V $(0.00 \%)$ pattern. While among females Type II $(75.00 \%)$ and Type I' $(9.00 \%)$ occurred more repeatedly followed by Type IV (7.00\%)> Type I (5.50\%)>Type III $(3.50 \%)$ with no Type V $(0.00 \%)$ pattern. There was no statistical significant difference observed in the distribution of lip prints with respect to each quadrant between males and females.

\section{DISCUSSION}

Finger prints and DNA comparison are most commonly used tools for the purpose of identification. However, it is useful to have several other methods of identification like cheiloscopy and palatoscopy as alternative tools in situations such as crime scenes, accidents and mass disasters. ${ }^{8,9}$ In this regard, lip prints could be a useful substitution to fingerprints and teeth for human identification. A major factor influencing lip prints is the method by which the prints are recorded. The status of the lips while recording is vital. As suggested by several authors a common problem encountered with traditional lip stick method is smudging or spoiling of lip prints leading to unidentifiable marks. ${ }^{10,11}$ Also, the amount and evenness, pressure and direction of the lipstick applied to the lips can disturb the accuracy of the records as well. ${ }^{12}$ Thus, in this study an easier photographic method with nil physical contact as adopted by Kapoor \& Badiye ${ }^{13}$ in Indian population is applied.

In our present study each individual had a distinctive lip print; no similar lip print pattern appeared in two subjects. This is in agreement with the results of most of the studies which concluded lip prints are not similar among different individuals thus confirming the uniqueness of 
the lip print. ${ }^{14,15,16}$ Type II lip pattern was almost equally distributed in both males and females at a proportion of $(75.50 \%)$ and $(75.00 \%)$ respectively, followed by Type I $(13.50 \%)$ in males and $(79.00 \%)$ in females. There was no Type V $(0.00 \%)$ lip prints observed in either of the sex in our study. Similar, to our finding predominance of Type II lip print was observed by Karki in Nepalese population, Verma et al, Patel et al and Gondivkar et al in Indian population. ${ }^{10,17,18,19}$ In contrary study findings of Ghimire et al. mentioned Type I as most frequently occurring lip pattern in Nepalese population. ${ }^{20}$ The overall pattern of distribution of lip prints in our study was in order Type II (75.25\%), Type I' (11.25\%), Type I (7.25\%), Type IV (3.50\%) and Type III $(2.75 \%)$. In males distribution of lip prints was in order Type II $(75.50 \%)>$ Type I' $(13.50 \%)>$ Type I $(9.00 \%)>$ Type III $(2.00 \%)$ with no Type IV $(0.00 \%)$ and Type V $(0.00 \%)$. In females distribution of lip prints was in order Type II $(75.00 \%)>$ Type I' $(9.00 \%)>$ Type IV $(7.00 \%)>$ Type I $(5.50 \%)>$ Type III $(3.50 \%)$ with no Type V $(0.00 \%)$. This is in accordance to the results of various studies done earlier which reveals that lip prints show ethnic and racial differences thus, it can be a suitable adjunct to identification of the person. ${ }^{10,17,18,19}$

In Nepali judicial system, inspite of the uniqueness of lip prints the practical application of this technique is lacking. As lip prints are unique, effort should be made to record the lip prints along with other traditional methods of identification. There is also need for similar studies on a larger sample size in both sexes to confirm the frequency of unchanging lip print patterns and to study the sex differences, in order to authenticate lip prints as a powerful forensic tool.

\section{CONCLUSION}

In the present study, lip prints of study participants did not match with each other. Thus, this finding validates that lip prints are distinctive similar to finger prints and thus have forensic significance. Smudging of lip prints is one of the major limitations of using lip sticks. Hence, photographic technique as adopted in our study could be constructive in recording lip prints to establish a morphologic database that might be of great value in civil and criminal litigations.

\section{RECOMMENDATION}

Population specific and gender specific studies in depth with larger sample size should be conducted in a larger scale so that a standard data base could be obtained and used for representing sex differentiation. Hence, analysis and testing of such data in various population groups has become absolutely essential.

\section{ACKNOWLEDGEMENTS}

The authors are thankful to all the subjects who participated voluntarily and cooperated in this study.

\section{REFERENCES}

1. Caldas IM, Magalhães $\mathrm{T}$ and Afonso A. Establishing identity using cheiloscopy and palatoscopy. Forensic Sci Int 2007; 165(1):1-9.

2. Sivapathasundharam B, Prakash PA and Sivakumar G. Lipprints (Cheiloscopy). Indian J Dent Res 2001;12(4):234-237.

3. Kasprzak J. Cheiloscopy. In: Siegal JA, Saukko PJ, Geoffrey C, Knupfer M, editors. Encyclopedia of Forensic Sciences. Vol. 1. London; Academic Press; 2000. p. 358361.

4. Suzuki $\mathrm{K}$ and Tsuchihashi $\mathrm{Y}$. A new attempt of personal identification by means of lip print. Can Soc Forensic Sci J 1971; 4(4):154-158.

5. Tsuchihashi Y. Studies on personal identification by means of lip prints. Forensic Sci 1974; 3(3):233-248.

6. Williams TR. Lip prints: Another means of identification. J Forensic Ident 1991; 41(3):190-194.

7. Vahanwahal SP and Parekh DK. Study of lip prints as an aid to forensic methodology. J Indian Dent Assoc 2000; 17(1):12-18.

8. Costa VA and Caldas IM. Morphologic patterns of lip prints in a Portuguese population: a preliminary analysis. J Forensic Sci 2012; 57(5):1318-1322.

9. El Domiaty MA, Al-gaidi SA, Elayat AA, Safwat MD and Galal SA. Morphological patterns of lip prints in Saudi Arabia at Almadinah Almonawarah province. Forensic Sci Int 2010; 200:179.e1-9.

10. Karki RK. Lip Prints - an Identification Aid. Kathmandu Univ Med J 2012; 38(2):55-57.

11. Karn A, Karna R, Bajgain P and Mandal B. Morphological Patterns of Lip Prints in Relation to Gender in a Defined Cohort. Eur J Forensic Sci 2015; 2(1):14-17.

12. Prabhu RV, Dinkar A and Prabhu V. Digital method for lip print analysis: A New approach. J Forensic Dent Sci 2013; 5(2):96-105.

13. Kapoor $\mathbf{N}$ and Badiye A. A study of distribution, sex differences and stability of lip print patterns in an Indian population. Saudi Journal of Biological Sciences 2017; 24(6):1149-1154.

14. Suzuki $K$ and Tsuchihashi $Y$. Personal identification by means of lip print. J Forensic Med 1970; 17(3):52-57.

15. Alvarez Segui M, Miquel Feucht M, Castello Ponce A and Verdu Pascual F. Persistent lipsticks and their lip prints: New hidden evidence at the crime scene. Forensic Sci Int 2000; 112(1): 41-47.

16. Ball J. The current status of lip prints and their use for identification. J Forensic Odontostomatol 2002; 20(2):43-46.

17. Verma $P$, Sachdeva SK, Verma KG, Saharan $S$ and Sachdeva K. Correlation of lip prints with gender, ABO blood groups and Intercommissural distance. North Am J Med Sci 2013; 5(7):427-431.

18. Patel S, Paul I, Madhusudan AS, Gayathri R and Sowmya GV. A study of lip prints in relation to gender, family and blood group. Int J Oral Maxillofac Pathol 2010; 1(1):4-7. 
19. Gondivkar SM, Indurkar A, Degwekar S and Bhowate R. Cheiloscopy for sex determination. J Forensic Dent Sci 2009; 1(2): $56-60$.
20. Ghimire N, Nepal P, Upadhyay S, Budhathoki SS, Subba A and Kharel B. Lip print pattern: An identification tool. Health Renaissance 2013; 11(3):229-233.

Authors Contribution:

STS- Concept and design of the study, collected data, statistically analyzed and interpreted, manuscript preparation; SMK- Critical revision of the manuscript; reviewed the literature, helped in preparing first draft of manuscript.

Work attributed to:

Department of Forensic Medicine, Manipal College of Medical Sciences, Pokhara, Nepal.

Orcid ID:

Dr Sidarth Timsinha- (io https://orcid org/0000-0003-3707-3855

Dr Suvarna Manjari Kar- (10) https://orcid.org/0000-0001-7741-7128

Source of Support: Nil, Conflict of Interest: None declared. 